\title{
Arquitectura arqueológica en el noroeste argentino: cien años de interés
}

\section{Archaeological architecture in northwestern Argentina: one hundred years of interest}

\author{
Ana Igareta ${ }^{1}$ \\ CONICET - Instituto de Historia, Teoría y Praxis de la Arquitectura y la Ciudad (HiTePAC), \\ Facultad de Arquitectura y Urbanismo, Universidad Nacional de La Plata
}

\begin{abstract}
RESUMEN
A través del análisis de una muestra de trabajos publicados, el presente artículo revisa el tratamiento dado a los restos arquitectónicos hallados en sitios arqueológicos del noroeste de la República Argentina entre los años 1877 y 1977. El objetivo de la revisión fue evaluar si el estudio de dichos restos fue o no tema de interés de la disciplina durante el periodo considerado y cuáles fueron las perspectivas desde las que se propuso su análisis. El resultado obtenido permite afirmar que, si bien de modo irregular, la arqueología argentina sí se interesó desde momentos tempranos por el estudio del registro construido, y que lo hizo mediante una heterogénea variedad de propuestas teórico-metodológicas cuyos criterios pueden ser relacionados con los postulados actuales de la arqueología de la arquitectura.
\end{abstract}

Palabras clave: arqueología argentina de los siglos XIX y XX; registro construido; antecedentes no sistemáticos de análisis arquitectónico; modelización de antecedentes.

\begin{abstract}
Through the analysis of a sample of published works, this article reviews the prior approach to architectural remains found at archeological sites in Northwestern Argentina between 1877 and 1977. The goal was to evaluate whether the study of such remains was a topic of interest among archaeologists during that period, and their proposed analytical perspectives. Results make it possible to affirm that, although irregularly, Argentine archeology was interested since its beginnings in the study of the built record. This was undertaken following a heterogeneous variety of theoretical-methodological proposals with criteria that might be linked to the postulates of the current Archeology of Architecture.
\end{abstract}

Key words: Argentine Archeology in the 19th and 20th centuries; architectural record; architectural analysis without systematic background; background modeling.

Recibido: 27-09-2019. Aceptado: 27-02-2020. Publicado online: 17-12-2020

Cómo citar este artículo / Citation

Igareta, A. 2020: "Arquitectura arqueológica en el noroeste argentino: cien años de interés", Arqueología de la Arquitectura, 17: e105. https:// doi.org/10.3989/arq.arqt.2020.013

Copyright: (c) CSIC, 2020. (c) UPV/EHU Press, 2020. Este es un artículo de acceso abierto distribuido bajo los términos de la licencia de uso y distribución Creative Commons Reconocimiento 4.0 Internacional (CC BY 4.0). 


\section{CONSIDERACIONES GENERALES}

El presente trabajo surge de la lectura de un texto en el que se revisaba la trayectoria de las investigaciones de la arqueología de la arquitectura en España e Italia y se advertía de las limitaciones implicadas en equipararla a la mera lectura estratigráfica de paramentos (Azkárate Garai-Olaum 2013: 281). Una revisión orientada a evaluar si dicha limitación podía afectar los estudios de arquitectura arqueológica que se desarrollan actualmente en la República Argentina nos permitió estimar que no existe un riesgo a corto plazo en tal sentido, dado que son contados los trabajos realizados en el país que han aplicado sistemáticamente la lectura de paramentos como método de análisis (cabe mencionar entre esos pocos a Páez 2002; Schávelzon 2012; Taboada 2016). En parte, tal ausencia de riesgo puede deberse a que recién en el curso de la última década la arqueología de la arquitectura se ha consolidado como campo de investigación a nivel local, por lo que los equipos que siguen esa línea de trabajo aún exploran las diversas posibilidades que ofrece y pueden capitalizar las experiencias y resultados previamente obtenidos por otros. Por otra parte, es posible que la lectura de paramentos sencillamente resulte un método de análisis inviable en un porcentaje significativo de los sitios con arquitectura, en los que el mal estado de conservación de los restos no permite el hallazgo de muros en pie sino apenas el de secciones de cimientos o de materiales constructivos desmoronados.

Por una particular combinación de factores -que incluyen agentes ambientales agresivos y débiles políticas de preservación patrimonial- la arquitectura arqueológica de la Argentina se encuentra peor conservada que la de países vecinos como Chile, Perú o Bolivia. Si bien existen numerosos conjuntos con buen nivel de integridad, sobre todo en el área andina donde el uso de la piedra como materia prima ha favorecido su conservación a largo plazo, en términos estadísticos el registro arquitectónico arqueológico argentino se encuentra mayormente fracturado y disperso. Eso hizo que, históricamente, los arqueólogos aplicaran variados métodos y herramientas para el estudio de los restos constructivos, con frecuencia surgidos como adaptaciones de las técnicas utilizadas para el análisis de otros restos hallados en los mismos sitios.

Tal vez por su multiplicidad y por lo variado de las situaciones del registro construido al que se enfrentaban, tales estrategias no se organizaron en un corpus teóricometodológico formal. En cambio, se desarrollaron a lo largo del siglo XX como propuestas integradas al cuerpo general de la investigación arqueológica, y su análisis quedó incluido en el de un referente material mucho más amplio, en el que otros componentes como la cerámica atrajeron la mayor parte de la atención. Dicha situación restó visibilidad a los estudios arqueológicos de rasgos construidos, lo que fue confundido con una falta de interés disciplinar: "En Argentina son muy pocas las investigaciones que analizan aspectos arquitectónicos más allá de lo meramente tipológico [hasta mediados de la década de 1980]" (Zarankin 1999: 120). Además, el hecho de que el componente arquitectónico de los sitios no fuera del interés particular de quienes estudiaron la historia de la disciplina (e.g. Fernández 1982; González 1985) hizo que las alternativas de su análisis a nivel nacional aparecieran escasamente mencionadas, lo que contribuyó a consolidar la noción general de falta de interés.

A fin de explorar la hipótesis de que la arqueología argentina sí se ocupó del estudio de los restos arquitectónicos pero que lo hizo desde una perspectiva plural, poco articulada y metodológicamente variable, realizamos una revisión de publicaciones con el objetivo de relevar el tratamiento dado al componente construido hallado en sitios arqueológicos desde los inicios de la disciplina y por el siguiente siglo. Específicamente analizamos textos referidos al noroeste argentino $(\mathrm{NOA})^{2}$, por ser la región cuyo territorio concentra desde el siglo XIX la mayor cantidad de proyectos de investigación arqueológica y al que refiere el mayor número de publicaciones científicas y de divulgación.

\section{PROPUESTA DE ANALISIS $Y$ OBSERVACIONES}

En las últimas décadas del siglo XIX, pasada la efervescencia de los primeros estudios arqueológicos cuya atención se centró en Pampa y Patagonia (Fernández 1982), el NOA se convirtió en la región arqueológica más explorada del país. Durante los siguientes 150 años los sitios allí ubicados fueron relevados, excavados y

El NOA es un área definida por un desarrollo cultural común que se extiende en sentido norte-sur desde la zona de mayor altitud de las provincias de Salta y Jujuy, Catamarca y La Rioja hasta el norte de la provincia de San Juan. En sentido oeste-este abarca desde la cordillera hasta las sierras subandinas y zona montañosa de Tucumán y Santiago del Estero, limitando con las tierras bajas chaqueñas (Caggiano y Sempé 1994: 227). Se encuentra subdividida en cuatro regiones arqueológicas: puna, quebradas, selvas occidentales y región valliserrana, cada una de las cuales posee sus propias particularidades ambientales y de desarrollo cultural (González 1979). 


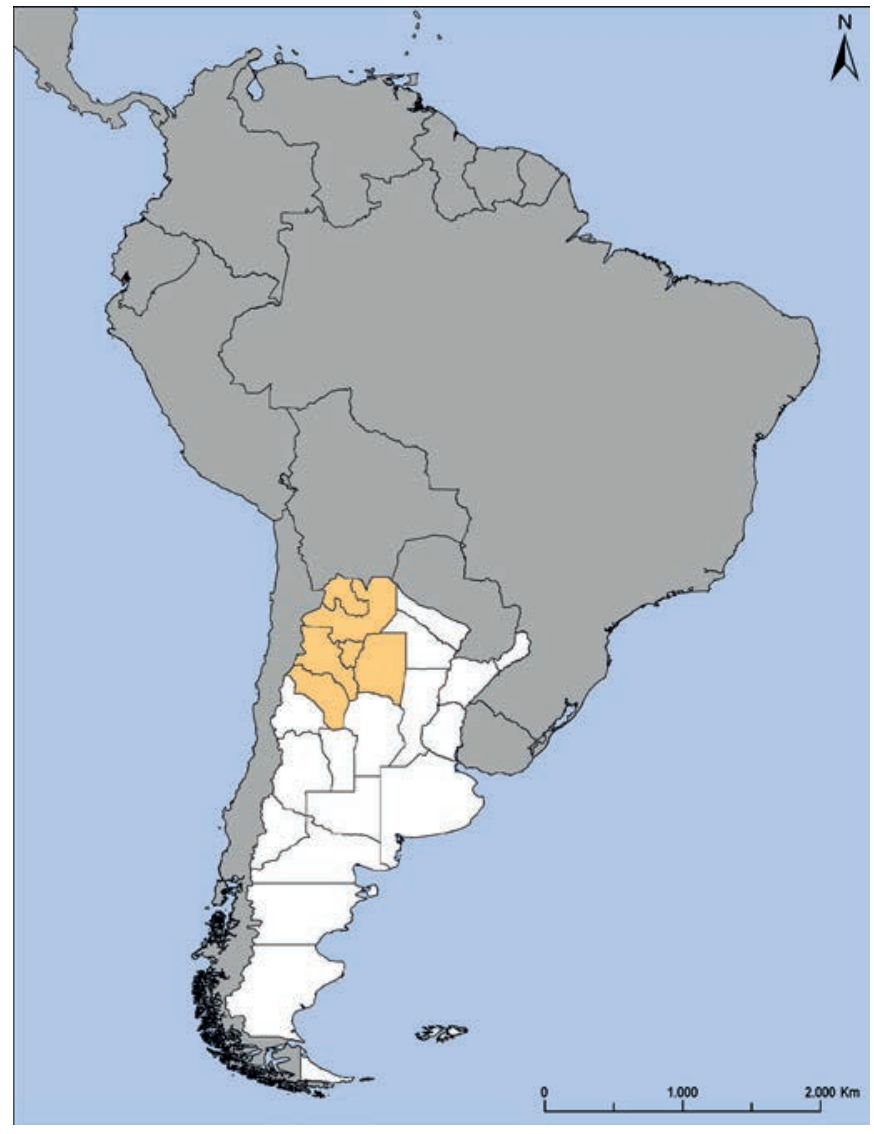

Figura 1. Ubicación del NOA en la República Argentina (D. Gobbo)

analizados de modo ininterrumpido, cada vez con mayor detalle, registrándose una progresiva mejora en los métodos de registro de datos y una complejización en las propuestas interpretativas, acorde con el desarrollo teórico de la disciplina a nivel nacional. Fue por ello que elegimos revisar textos referidos a la región que abordaban el análisis de sitios arqueológicos con restos arquitectónicos publicados entre 1877 y 1977 (en términos generales, el primer siglo de publicaciones arqueológicas argentinas). Teniendo en cuenta el enorme volumen de textos aparecidos durante este periodo $-\mathrm{y}$ que su análisis exhaustivo excede las posibilidades del presente artículo- decidimos relevar la obra de los autores considerados como principales referentes para la región, revisando su producción para el lapso en cuestión incluida en el programa de Arqueología Argentina (materia de grado del último año de la licenciatura en Antropología de la Facultad de Ciencias Naturales y Museo de la Universidad Nacional de La Plata, plan 1985 - modificado). A ellos sumamos algunos otros autores que, a nuestro entender y basados en nuestro conocimiento del tema, resultaban relevantes para el análisis propuesto.
Examinamos las publicaciones de 51 autores, identificando menciones a restos arquitectónicos en la obra de 33 de ellos, y procedimos luego a registrar brevemente el tratamiento dado a cada conjunto (descripción, relevamiento, registro gráfico, asignación cronotipológica, interpretación funcional, propuesta de filiación cultural). Siguiendo a Taboada, no solo revisamos aquellos textos que desde su título u objetivo puntual reflejaban interés por la problemática, sino que consideramos otros aparentemente no específicos pero cuyo contenido también revelaba un interés por el registro arquitectónico (2016).

Esperablemente, observamos que la producción de cada arqueólogo estuvo inmersa en las concepciones teóricas propias de su época y de su interés, y que el análisis de los restos construidos se vio tan influido por ello como el resto del registro material ${ }^{3}$. Pero una revisión detenida de las publicaciones y de sus imágenes mostró, además, que los trabajos realizados por individuos que poseían algún tipo de formación técnica (o en colaboración con estos) resultaron en registros más sistemáticos, detallados y comprensivos de la arquitectura arqueológica que los de otros investigadores. Con frecuencia, los mismos arqueólogos reconocen las dificultades implicadas en el registro de restos construidos en ausencia de personas idóneas ("yo no quise que se tocasen porque no tenía ni dibujante ni fotógrafo conmigo para que se consignase la colocación del yacimiento", Lafone Quevedo 1902: 262) tanto como la importancia de su participación en caso de hallazgos complejos ("Elegidas las estructuras habitacionales que debían ser estudiadas en ambos sectores, se procedió a realizar un relevamiento completo por parte de un técnico", De la Fuente 1972: 5). Habida cuenta de la cantidad de variables y procesos involucrados en la construcción de hasta el más sencillo de los elementos arquitectónicos, resulta comprensible que -independientemente de su posicionamiento teórico- los investigadores que se hallaban familiarizados con ciertas lógicas subyacentes a los procesos constructivos supieran ver y representar mejor este registro que el resto de sus colegas, y que dicha situación destacara aún más cuando los restos a relevar integraban conjuntos arquitectónicos complejos.

En algunos casos, quienes registraron los sitios fueron quienes los interpretaron, como ocurrió con el ingeniero topógrafo y agrimensor Lange y sus relevamientos de las ruinas de Watungasta, Catamarca (1892a), o con

\footnotetext{
Para una revisión de la evolución de los estudios de la arquitectura arqueológica del NOA desde una perspectiva teórica ver Taboada 2003, capítulo 2.
} 
el notable trabajo del arquitecto Greslebin (1940) en Tambería del Inca, La Rioja, cuyos trabajos recogen información precisa de los conjuntos que utiliza luego para generar interpretaciones sobre sus procesos constructivos y funcionales. En otros casos, la tarea técnica se enfocó tanto en el registro minucioso en el terreno como en la elaboración de reconstrucciones gráficas de la arquitectura de los sitios de acuerdo con las propuestas interpretativas de los arqueólogos. Tal fue el caso del mismo Greslebin como dibujante de Debenedetti durante su relevamiento de El Alfarcito, Jujuy (Debenedetti 1918) o del arquitecto Alvis como colaborador temprano de Cigliano en sitios de Salta $(1973,1975)$ y luego de Raffino en Catamarca (1977 y posteriores). En cierto modo, estas exitosas experiencias fueron un ejercicio de interdisciplina antes de que tal concepto se popularizara entre los investigadores.
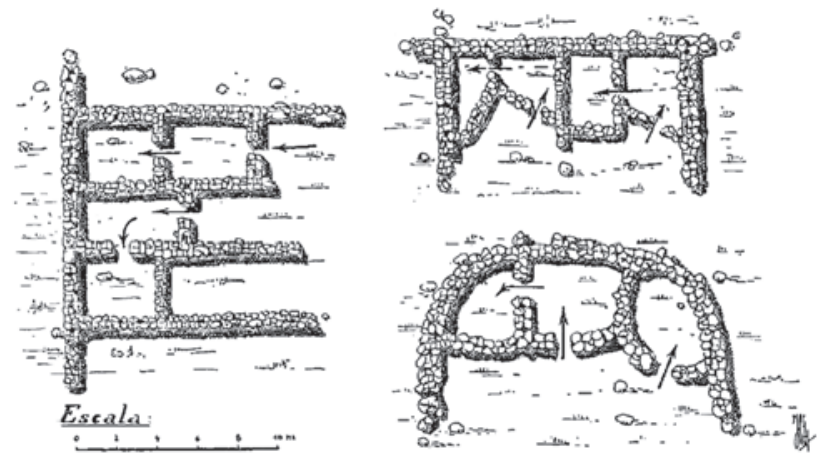

Figura 2. "Figura 7-Ruinas de las viviendas cuyos muros están apoyadas contra las terrazas" incluida en Debenedetti (1918: 296) y realizada por Greslebin. Nótese el detalle volumétrico, los sombreados y las flechas que marcan el sentido de circulación inferido dentro de las viviendas.

Resultó interesante observar cómo durante el periodo relevado, y cada vez más a medida que avanzó el siglo XX, los arqueólogos no solo se ocuparon de estudiar los restos arquitectónicos que aún se hallaban en pie en los sitios, sino que analizaron los componentes constructivos presentes en estratigrafía, dispersos o ausentes de los sitios, y utilizaron la información obtenida para elaborar propuestas interpretativas sobre los procesos constructivos y/o las formas de uso de los antiguos edificios. Boman, por ejemplo, observó la ausencia de aberturas en los restos de muros de edificios que visitó en la Puna, y postuló que el acceso al interior de los recintos debió haberse realizado desde los techos (Boman 1908). González, por su parte, propuso que las perforaciones halladas en el suelo en el interior de diversos recintos excavados en Corral de Ramas y otros sitios de Catamarca eran evidencia del uso de "postes que a modo de columna, sostuvieron la techumbre [...] El resto de las paredes debió ser de ramas o de barro y ramas, lo mismo que el techo. La presencia de sólo 2 huellas definidas de poste sugiere el empleo de vigas largas y únicas" (González 1954a: 127). Sustenta su propuesta en el hallazgo en estratigrafía de pequeñas secciones de maderas carbonizadas asociadas a algunos de los pozos y atribuye la desaparición del resto a un incendio intencional de las estructuras por parte de sus ocupantes, antes de abandonarlas (González 1954a: 129). Si bien se trata de breves menciones y propuestas altamente especulativas, resulta innegable que muchos autores se esforzaron por ir más allá de la mera descripción de rasgos arquitectónicos y avanzar en la comprensión de los conjuntos.

La revisión bibliográfica permitió proponer que, independientemente de su fecha de publicación, los trabajos pueden ser reunidos en cuatro grandes conjuntos o modelos de acuerdo con la perspectiva desde la cual los autores abordaron el análisis del registro arquitectónico. No pretendemos que dichos modelos contengan o agoten todas las posibilidades de organización de estos textos, sino reconocerlos como una opción válida para sistematizar las propuestas más repetidas. De igual modo, no nos propusimos evaluar el posible acierto o error de las interpretaciones presentadas por cada autor, sino explorar su interés por el análisis del registro arquitectónico presente en sitios arqueológicos y observar cuáles son los elementos que destacan en cada obra. Como podrá notarse, con frecuencia los restos arquitectónicos de un mismo sitio son susceptibles de ser asignados a más de un modelo de acuerdo con el planteo de uno u otro autor o con la escala en que se desarrolló dicho análisis, lo que da cuenta de la diversidad de perspectivas de abordaje identificadas.

\section{ANTES DE LOS MODELOS: LIBERANI Y HERNANDEZ Y ARQUITECTURA DE TUMBAS}

La atracción que generaron las ruinas del NOA desde momentos tempranos sobre los investigadores que visitaron la región quedó plasmada en el trabajo de von Tschudi de 1858 referido al Fuerte de Andalgalá, provincia de Catamarca -aunque, en palabras de Raffino, el resultado fue un relato algo fantástico (2007: 78)-. Dos décadas después Liberani y Hernández presentaron 
Excursión arqueológica en los Valles de Santa María, Catamarca, considerada como la primera publicación formal de la arqueología argentina y a la que deseamos dedicar unas líneas en particular. El texto presenta los resultados de su expedición al sitio de Loma Rica de Shiquimil, Catamarca, donde realizaron excavaciones en el interior de los restos de unos recintos de piedra y recuperaron un interesante conjunto de piezas de cerámica, muy codiciadas en la época. Pero las primeras ilustraciones de la obra no corresponden a dichas piezas sino a una "vista general" del sitio; al "plano de la población antigua ubicada en la parte superior de Loma Rica"; al "croquis de una habitación (Pilca)" y a una "vista de la necrópolis" (Liberani y Hernández [1877] 1950: 67). Se trata de ilustraciones sencillas y sin escala pero con sus correspondientes referencias cardinales, que presentan a las ruinas ubicadas en la geografía que las rodea y con algunos detalles de interés. Aunque de modo escueto, los autores brindan en el texto que acompaña a las ilustraciones datos sobre los restos arquitectónicos hallados; e. g.:

La altura de estas paredes varía de 1 a $2 \mathrm{~m}$ sobre el nivel del suelo mientras su espesor mide $1 \mathrm{~m}$ apenas. Algunas están interrumpidas y juzgamos que estas interrupciones serían tantas puertas de comunicación ya sea con exterior, ya con el interior de las casas... Los materiales de que están construidas las paredes son piedras rodadas, generalmente graníticas o cistosas, sin indicio aparente de argamasa (Liberani y Hernández [1877] 1950: 114).

Luego intentan una propuesta de identificación de la función original de algunos de los edificios articulando los datos constructivos con la información del material recuperado durante las excavaciones realizadas, esbozando una propuesta referida al posible carácter defensivo del sitio.

Analizando otra problemática, Nastri (2001: 34) propuso que este trabajo inauguró una línea de presentación de datos que la arqueología regional siguió desde entonces, con pocas variaciones: la descripción general del asentamiento y su territorio, la descripción específica de las estructuras arquitectónicas (fundamentalmente a partir de planos y dibujos) y la descripción detallada de piezas recuperadas en los cementerios asociados a los poblados. Según pudimos apreciar, esta secuencia identificada por Nastri para valles calchaquíes a fines del siglo XIX va a convertirse en el modelo de presentación de un conjunto más amplio de sitios arqueológicos del
NOA: la de los sitios con arquitectura. Así, durante las siguientes décadas, docenas de trabajos van a reproducir un esquema en el que los restos de construcciones son el componente mencionado y caracterizado en primer lugar, para identificar el "tipo de sitio", y a continuación se brindan detalles sobre el registro mueble hallado durante las excavaciones.

Los yacimientos arqueológicos de Chañarmuyo pueden dividirse en dos series perfectamente bien caracterizadas: los que llamaremos de los barreales y los de los pedregales. Los primeros están ubicados sobre la margen izquierda del río; los segundos se extienden sobre los campos pedregosos situados inmediatamente a espaldas de los barreales... En los barreales no existen vestigios de viviendas, aun cuando supongo que éstas existieron en abundancia, dada la gran cantidad de restos de alfarería que se encuentran dispersos. Las viviendas fueron de barro o de quincha, especies de ramadas [...] En los pedregales las construcciones fueron de piedra: las pircas, aunque no en buen estado de conservación, se mantienen todavía en pie. No alcanzan a tener más de 70 centímetros de altura y, creo, que muchas de ellas son verdaderos cimientos sobre los cuales se terminó el edificio mediante adobes o simple barro amasado (Debenedetti 1919: 397).

El trabajo de Liberani y Hernández fue pionero además en el relevamiento, excavación y presentación de un tipo específico de construcciones, las tumbas, cuyo análisis va a dominar el panorama arqueológico argentino de las primeras décadas del siglo XX (Taboada 2003: 20). Los textos revisados dan cuenta de cientos de ejemplos de construcciones subterráneas halladas de modo aislado, en directa asociación con estructuras de vivienda, cultivo o almacenamiento, o reunidas en cementerios y necrópolis. $Y$ aunque el énfasis descriptivo e interpretativo de los arqueólogos del NOA se enfocó casi obsesivamente en los objetos que conformaban los ajuares hallados en las tumbas (incluso por encima del de los restos de los individuos enterrados), las características arquitectónicas de las estructuras funerarias y su relación con otros componentes construidos nunca pasaron inadvertidas.

En las inhumaciones encontramos un elemento más definitorio para el establecimiento de diferenciaciones culturales. En la Quebrada de Humahuaca [...] se efectuaron de preferencia en los pisos de las viviendas $[\ldots]$ 

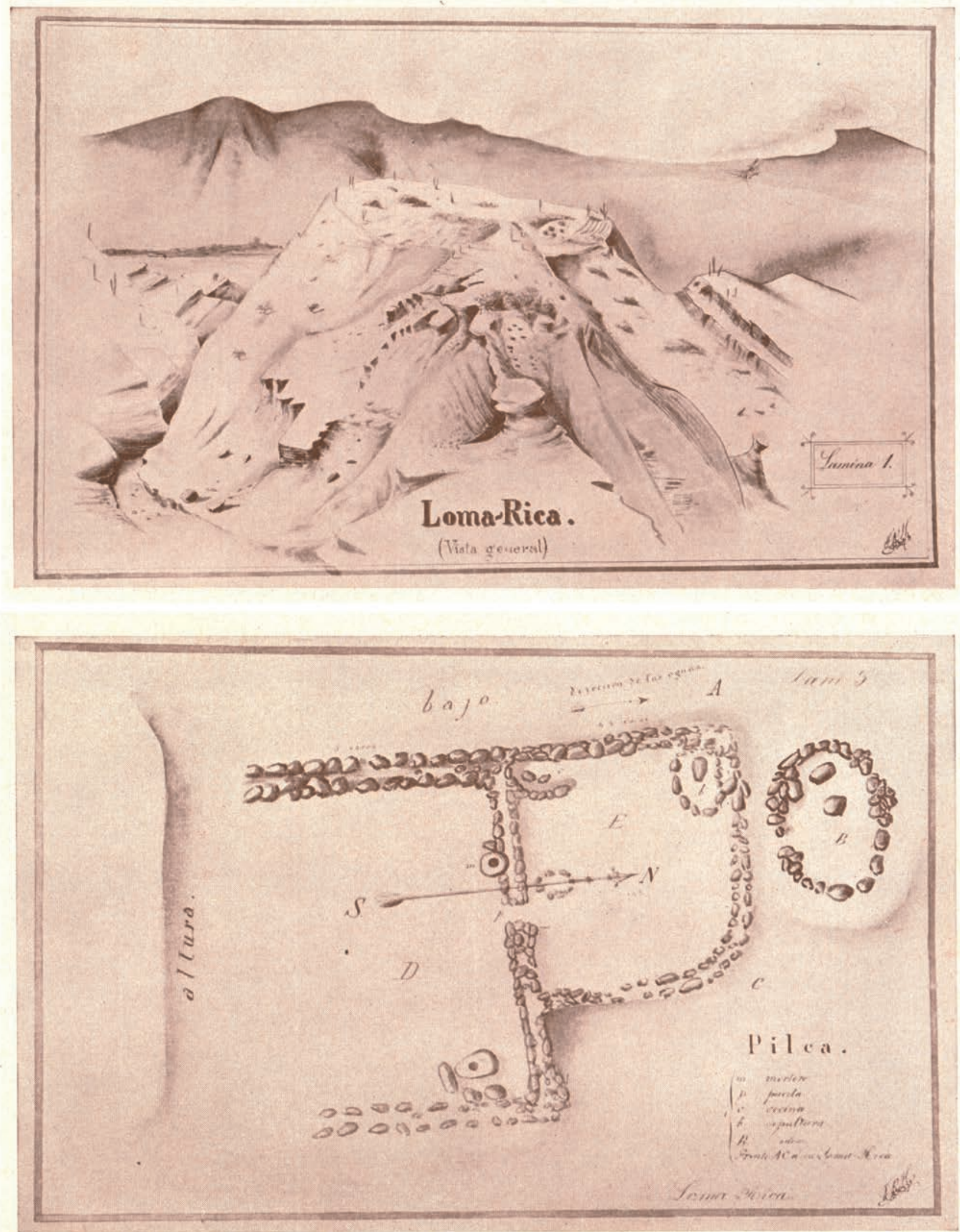

Figura 3. Vista general del sitio Loma Rica (arriba) y croquis de una habitación (abajo), incluidas en el texto publicado por Liberani y Hernández con detalles de las primeras intervenciones realizadas en el sitio ([1877] 1950: 52). 
En cambio, en Yavi Chico, si bien conocemos muchos otros aspectos de la cultura de los indígenas que allí vivieron, no sabemos aún de qué manera sepultaron a sus muertos. Podemos señalar por lo menos que no lo hicieron en las viviendas. [...] Nuestras investigaciones estuvieron destinadas principalmente a la obtención de secuencias estratigráficas y al estudio de viviendas y otras construcciones (Krapovickas 1970: 120).

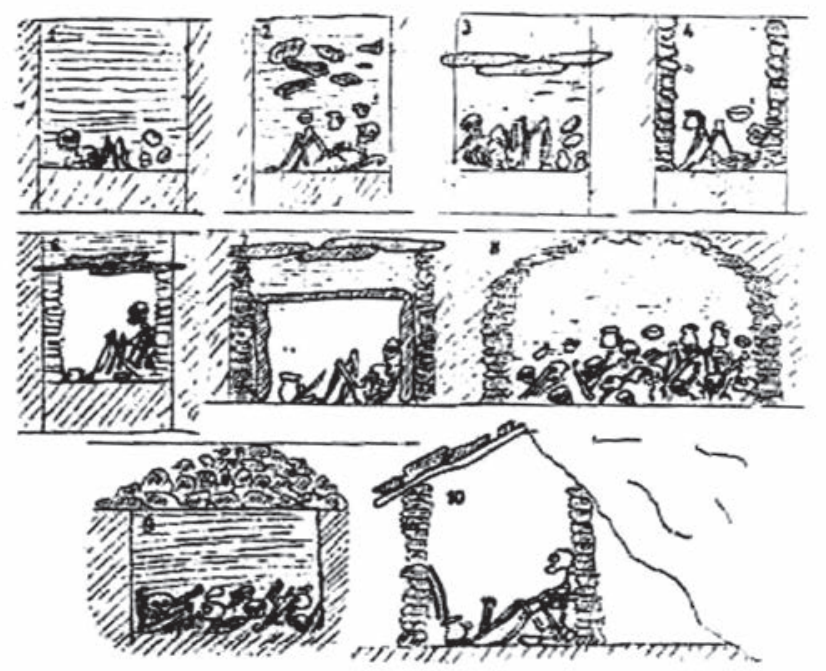

Figura 4. Un ejemplo de temprano registro gráfico a mano alzada de los tipos de construcciones funerarias halladas en sitio del NOA (Schuel 1929: 1451, modificado por D. Gobbo).

El registro de las materias primas y técnicas utilizadas, la relación entre morfología y contenido, la identificación de tipos y su asignación a culturas arqueológicas, los cambios en la morfología y tecnología constructiva como marcador cronológico y evidencia de cambio cultural, todos estos temas fueron objeto de estudio.

El detalle de la construcción de estas tumbas abovedadas es el siguiente: El plan o suelo se presenta cuidadosamente embaldosado con trozos de lajas ó piedras chatas de espesor variable, colocadas de modo que quede un piso uniforme. Las paredes, de forma circular, se hallan revestidas por otras lajas grandes, paradas y superpuestas, con los intersticios que quedan entre ellas ocupados por otras pequeñas, á fin de que el conjunto presente una superficie lo más lisa y unida posible. A una altura de ochenta centímetros, más o menos, empieza a formarse la bóveda que cierra la tumba. Para esto han colocado trozos largos de piedra, recostados [...] Esta operación se repite hasta que la bóveda cierre completamente y las últimas piedras queden al nivel del suelo más o menos.
El trabajo, en su conjunto, no puede ser mejor hecho, y dado los elementos de que podían disponer, se nota en todos una proligidad en la elección de la piedra que demuestra la importancia que para los indios tenía, en sus creencias religiosas, la conservación de los muertos (Ambrosetti 1897: 54).

\section{MODELO 1 - RASGOS}

Una quinta parte de los textos revisados menciona la presencia de restos arquitectónicos aislados en los sitios arqueológicos de los que se ocupan, que abarcan desde tumbas simples, partes de cimientos, secciones de muros con unas pocas hiladas conservadas hasta recintos de diverso tamaño y morfología ${ }^{4}$. Los autores se interesan en estos casos por describir en detalle las características de las construcciones, pero a una escala que nunca alcanza la de todo el conjunto arquitectónico o el sitio (Taboada 2003: 19). Casi en su totalidad, las descripciones refieren a estructuras construidas con piedra, un tipo de arquitectura que, si bien no fue la única, como dijimos predominó en el NOA prehispánico, aunque son varios los autores que proponen el uso de adobe y quincha como materiales constructivos entre las poblaciones tempranas de la región, articulando rasgos observados en el registro arquitectónico con rasgos inferidos:

Estos nuevos tipos de habitación son de gran importancia pues no solo abren novísimas perspectivas en lo que se refiere a la evolución cultural del área, permitiendo vislumbrar desde ya los pasos seguidos en los cambios habidos en los distintos tipos de viviendas en las diferentes culturas que la habitaron sino también por las proyecciones y sugerencias [...] que esas habitaciones ofrecen al ser comparadas con otras de distintos lugares [...] la arquitectura basada en la construcción de recintos o habitaciones con muros de piedra (pirca) pertenecen a la última y más reciente capa cultural del N.O. Esta etapa cultural fue precedida por otras que usaron habitaciones hechas de material perecible (González 1954b: 122).

Los esfuerzos por identificar la antigüedad, origen cultural o función de los restos construidos es una

\footnotetext{
4 Por cuestiones de espacio no consideramos en el presente trabajo los textos que hacen referencia a restos de andenes de cultivo, acequias, canales, represas, caminos o puentes, y nos limitamos a aquellos que se ocuparon de estructuras de vivienda, actividades y almacenamiento, pero debe tenerse en cuenta que se trata de un extenso conjunto de ejemplos y de publicaciones.
} 
constante, por lo general a través de la extrapolación de datos obtenidos del análisis de objetos recuperados en estratigrafía; "La clave más segura para la ubicación cultural de esta vivienda la proporciona el estudio de los fragmentos de alfarería" (González 1954b: 129).

En unos pocos casos los arqueólogos apenas mencionan la presencia de restos de construcciones en los sitios, mientras que en la mayor parte de estos avanzan en la descripción y el registro de las materias primas y las técnicas utilizadas, e intentan propuestas clasificatorias morfológicas. Los restos arquitectónicos aparecen nombrados utilizando categorías funcionales -vivienda, patio, corral, depósito, muralla, sala- pero se trata generalmente de propuestas no contrastadas, más interesadas por dar cuenta de la presencia del rasgo que por investigar su función real (Taboada 2003: 19).

Con frecuencia, en los trabajos de la primera mitad del siglo XX los autores identifican y caracterizan un determinado rasgo constructivo y luego lo asignan mecánicamente a una cultura arqueológica. Por ejemplo, en 1936 Serrano publicó un breve texto en el que sintetizó los que, a su entender, constituían los rasgos básicos de la arquitectura diaguita - una de las sociedades indígenas que habitaba el NOA al inicio de la conquista-: muros de bloques de piedra, presencia de dinteles, evidencias de uso de bóveda en saledizo y techos de una sola agua son algunos de los mencionados para sitios de las provincias de Tucumán y Catamarca (Serrano 1936: 53). La aparición a nivel local de elementos constructivos como resultado de la influencia de culturas peruanas o bolivianas fue otra de las temáticas discutidas por los arqueólogos del NOA, tanto como la posibilidad de que ciertos rasgos solo hubieran aparecido en la arquitectura local a posteriori de la conquista ibérica.

Boman, atraído por el brillo de la civilización peruana del último momento se constituyó en acérrimo defensor de ese origen $[\ldots]$ y considerando probada históricamente la dominación del noroeste por los Incas, afirmó que la cultura de este sector de nuestro territorio provenía de ellos. Sin embargo, Ambrosetti (1899), años antes, con su habitual genialidad, había preconizado para la civilización calchaquí un origen extraño e independiente del Perú [...] Debenedetti (1912), por su parte, cree encontrar restos de la cultura de Tiahuanaco en todo el noroeste [...] Es admisible la existencia en el noroeste de una serie de rasgos que denotan la presencia de un fondo común, que entronca en nuestra concepción de lo andino (Lafón 1958: 10).
Varios de los autores cuyos trabajos se incluyen en este modelo utilizaron recurrente $-\mathrm{y}$ cuestionablemente- datos históricos y analogías etnográficas para generar explicaciones sobre determinados rasgos de la arquitectura arqueológica, esforzándose por conectarla con tradiciones y prácticas constructivas aún vigentes entonces entre las poblaciones locales (Spengler 2008: 25). Por ejemplo, en un texto de 1937, Ardissone propuso una tipología clasificatoria para la arquitectura de los silos utilizados por las poblaciones de la Quebrada de Humahuaca, Jujuy, que incluye tanto ejemplos contemporáneos como casos arqueológicos. En su opinión, el uso de graneros subterráneos construidos en piedra para el almacenamiento de grano se remonta a tiempos prehispánicos y utiliza los hallazgos y datos relevados por otros arqueólogos para sustentar su propuesta (Ardissone 1937: 133).

Además de los ya citados puede incluirse en este modelo el interesante texto de Márquez Miranda de 1937 en el que sistematiza y presenta los rasgos de la "arquitectura aborigen" que observa en sitios de Salta y el de Lahitte y Calandra (1975), pero el estudio de rasgos o componentes arquitectónicos aislados prácticamente desaparece durante la segunda mitad del siglo $\mathrm{XX}$, cuando la noción de estudios contextuales se instala en la disciplina y los trabajos pasan a enfocarse no en los objetos o las estructuras sino en las relaciones de conjunto.

\section{MODELO 2 - RUINAS, PUEBLOS Y FORTALEZAS}

El corpus de restos arquitectónicos de los que se ocupó mayoritariamente la arqueología del NOA durante el periodo revisado corresponde a "las ruinas de...", "el pueblo de..." y/o "el pucará ${ }^{5}$ de...", instalaciones en las que se articulan entre media docena y una centena de recintos de variada morfología y tamaño, muchas veces asociados a cementerios, y que fueron utilizadas con diversos propósitos. Estas investigaciones superan la escala de análisis de rasgos o componentes que caracteriza al modelo anterior y se orientan, en cambio, al

\footnotetext{
Denominación genérica dada en el área andina meridional a grandes complejos arquitectónicos de piedra construidos desde comienzos del siglo $\mathrm{X}$ y hasta la conquista inca en el siglo XV. Originalmente se les asignó una función estrictamente militar a modo de "fortalezas" (Ambrosetti 1912), pero investigaciones posteriores han propuesto que se trató de instalaciones urbanas de carácter residencial con rasgos defensivos (Nielsen 2001).
} 
estudio de conjuntos de restos construidos; además, los autores comienzan a analizar los procesos de obtención y procesamiento de las materias primas y a relacionar la función de la arquitectura con el paisaje que la rodea.

Buen ejemplo del tipo de texto incluido en este modelo es el de Bruch de 1911, en el que reúne sus observaciones sobre dieciséis sitios con arquitectura ubicados en las provincias de Catamarca y Tucumán. Bruch visita cada uno de ellos y se detiene en la descripción de sus "construcciones antiguas", relevando -de modo algo desordenadolas características de cada uno y la relación entre sí, pero detallando además sus diferencias tecnológicas.

Para la edificación los Quilmes se valieron del abundante material que el cerro les proporcionaba, es decir, la piedra laja, micaesquistosa y filitas sericíticas, usadas tal como se separa por su propio clivaje. Estas lajas, se comprende, son muy apropiadas para la edificación y han sido superpuestas con cuidado sin el empleo de cemento alguno, formándose con ellas paredes perfectamente perpendiculares, casi siempre de uno pero hasta de dos metros de espesor. [...] Por regla general, todos los muros son lisos del lado de adentro y perfectamente verticales; á menudo, la base se halla reforzada con piedras grandes, chatas ó lajas clavadas de punta, sobre todo en los sitios donde el suelo se presenta muy inclinado. Al contrario, por fuera los muros son siempre más desiguales é irregulares. [...] Las construcciones del pueblo son cuadrangulares y redondas; las últimas son más escasas y las dimensiones menores, pero, á juzgar por las pocas que hemos podido observar, parecen estar en relación con las primeras (Bruch 1911: 21).

Trabajos como los de Lange (1892a, 1892b), Quiroga (1896, 1901), Lafone Quevedo (1902), Ambrosetti (1906, 1907, 1912), Boman (1908, 1916), Debenedetti (1908, 1918, 1930), Schuel (1929), Casanova (1933), De Aparicio (1937, 1940-1942), Greslebin (1940), Márquez Miranda (1937) y Salas (1945) abordan el análisis de extensas instalaciones desde diversas perspectivas descriptivas e intentan la elaboración de propuestas tipológicas como herramienta para su clasificación. Abundan en estas publicaciones los planos, cortes, vistas, plantas y detalles de los sitios, acompañados de un progresivo incremento del uso de fotografías que muestran detalles de las estructuras y los conjuntos.

En este modelo se incluyen algunos de los primeros estudios de arquitectura colonial realizados en el país, como el breve análisis de Ambrosetti de las transformaciones constructivas sufridas por el casco de una estancia del siglo XVII ubicada en Molinos, Salta (Ambrosetti 1903), o el de Cáceres Freyre de las ruinas del Fuerte del Pantano, La Rioja, un interesante caso de arquitectura defensiva en adobe, tapia y madera identificado como de origen hispánico y cuyo estado de deterioro es explicado a partir de la observación de la concurrencia de agentes ambientales y antrópicos (Cáceres Freyre 1937, 1955). También cabe mencionar el trabajo de Furque, quien identificó con precisión evidencias de superposición constructiva en la arquitectura de unas ruinas catamarqueñas "no cabe duda de que hubo allí una población española, siendo lo más probable que fuese abandonada y ocupada después por los indios" (Furque 1900: 169), aunque equivocó el orden de las sucesivas ocupaciones (Igareta 2009).

El estudio de ruinas generó interesantes discusiones entre los arqueólogos; por ejemplo, Márquez Miranda objetó la propuesta de Bruch según la cual los andenes de cultivo de ciertos sitios eran efectivamente construcciones, dado que carecían de recintos de habitación asociados (Márquez Miranda 1940: 230). Debenedetti y Greslebin, por su parte, discreparon en su apreciación sobre el estado de conservación de los muros de los recintos de Tambería del Inca, dado que el primero afirmó que se hallaban perfectamente conservados mientras que el segundo sostuvo que estaban significativamente deteriorados y que la apreciación de Debenedetti derivaba de una mala comprensión de las características arquitectónicas del sitio (Greslebin 1940: 11).

En la década de 1950 la arqueología argentina se vio fuertemente impactada por el concepto de patrón de asentamiento propuesto por Willey para sitios de la costa norte de Perú y por las posibles aplicaciones del uso del dato arquitectónico como evidencia para estudiar cambios sociales a largo plazo (Willey 1953). Desde perspectivas muy diferentes, los trabajos de Lafón (1954), Krapovickas (1955), González y Núñez Regueiro (1960), González (1966), Alfaro y Suetta (1970), Núñez Regueiro (1971, 1974), Cigliano y Raffino (1973, 1975), Raffino (1975), De la Fuente (1973b), Pérez Gollán y Heredia (1975) y Sempé (1977a; 1977b) se interesaron por el concepto y por los procesos implicados en la apropiación y uso del espacio por parte de los constructores de conjuntos arquitectónicos prehispánicos. Ello, sumado a la adopción definitiva del método estratigráfico, amplió radicalmente el universo de análisis y de las propuestas interpretativas de las dinámicas sociales de la región. 
Para la segunda mitad del siglo XX el volumen de información ya disponible sobre los edificios prehispánicos permitió interesantes trabajos de recopilación y síntesis, como el realizado por Madrazo y Ottonello (1966) para la Puna; tomando en cuenta el ambiente natural en que se ubicaban diversas instalaciones, los autores clasificaron las ruinas de los poblados de acuerdo con su morfología interna (grado de dispersión o aglutinamiento) y propusieron una tipología para las unidades de residencia basada en una articulación de criterios morfológicos y funcionales.

\section{MODELO 3 - CIUDADES}

La tercera de las problemáticas que desde temprano captó el interés de los arqueólogos argentinos fue el posible carácter urbano de algunas de las extensas instalaciones identificadas en el NOA. En el marco en una discusión más amplia que enfrentó a quienes sostenían que el fenómeno urbano se había desarrollado en la región solo $a$ posteriori de la conquista ibérica con quienes afirmaban la existencia de un urbanismo prehispánico, muchos trabajos se enfocaron en definir qué rasgos debía presentar la arquitectura de un sitio para ser considerada como ciudad.

Algunos autores como Ambrosetti (1897, 1907) asumieron inductivamente desde momentos tempranos que las ruinas que analizaban eran de antiguas ciudades y se dedicaron a la exploración y registro de sus características, interesándose por dar cuenta de las variaciones arquitectónicas observadas: "de cuya base arrancan las diversas construcciones que se dirigen ya hacia abajo, la ciudad propiamente dicha; ya hacia arriba: la fortaleza y el campo de refugio fortificado" (Ambrosetti 1897: 35). Otros arqueólogos se interesaron por identificar la función específica de ciertos edificios y por determinar el rol que jugaron en el contexto urbano en el que se insertaron; Márquez Miranda, por ejemplo, planteó la existencia de una "arquitectura fiscal" inca, representada por los grandes silos hallados en ciudades y cruces de caminos, y cuya presencia evidenciaba el control imperial sobre sitios del NOA (Márquez Miranda 1940: 132). Asimismo, reconoció un uso diferencial de materias primas en edificios de una misma cultura y una misma región, proponiendo que daban cuenta de una diferencia de clases:

En la parte de la sierra, los adobes y la pirka constituían los elementos integrantes de la edificiación popular, habitaciones de los hatunrunas u hombres del pueblo, pero los edificios más importantes -templos, palacios, fortalezas- poseían muros de piedra cuidadosamente seleccionadas, terminadas en ángulos rectos y de formas cuadradas (Márquez Miranda 1940: 126).

Las ciudades coloniales, el sitio elegido para su fundación y las características de su arquitectura fueron otros de los temas de interés de las investigaciones incluidas en este modelo, cuyos primeros ejemplos se remontan a los trabajos de Lafone Quevedo (1898) y sus esfuerzos por dilucidar, a partir del análisis documental, la ubicación de las primeras El Barco y Santiago del Estero. A estos trabajos se sumaron luego otros como el análisis de las ruinas de Ibatín, sitio de la primera fundación de San Miguel de Tucumán en el siglo XVI, en los que Gramajo recurrió permanente al uso de documentos históricos para interpretar hallazgos arquitectónicos:

... según los Documentos Coloniales, hacia 1570 existían fábricas de tejas y ladrillos de factura acabada, lo cual revela una asimilación de la técnica española en la materia. La aparición de estos materiales nos llevó a tratar de descubrir los pavimentos respectivos de los edificios para lo cual practicamos nuevos sondajes en distintos puntos siempre con resultados negativos, excepción hecha de un piso de baldosas cerámicas descubierto en el edificio de los Jesuitas, a $0,80 \mathrm{~m}$ debajo del piso actual. Estas baldosas de forma rectangular fueron especialmente trabajadas para este fin, con un chanfle permietral, lo que permite colocarlas a junta cerrada (Gramajo 1976: 146).

El desarrollo de los estudios sobre el urbanismo prehispánico del NOA alcanzó un punto notable en la década de 1960 con el trabajo realizado por Cigliano -y luego continuado por Raffino- en las ruinas de la ciudad de Tastil, ubicada a más de $3000 \mathrm{~m} \mathrm{s.} \mathrm{n.} \mathrm{m.} \mathrm{en}$ provincia de Salta. Durante años, Cigliano y su equipo se dedicaron a la excavación sistemática de parte de los 1161 recintos relevados en sus casi $110.000 \mathrm{~m}^{2}$ de superficie y a la clasificación de las unidades construidas identificadas de acuerdo con criterios morfofuncionales (Raffino 2007: 127). El estudio de Tastil no solo proporcionó evidencias concretas de la existencia de ciudades en el NOA antes del avance inca, sino que generó un modelo comparativo de desarrollo cultural a nivel regional basado en el ambiente ecológico, en que los rasgos arquitectónicos jugaron un papel clave. 


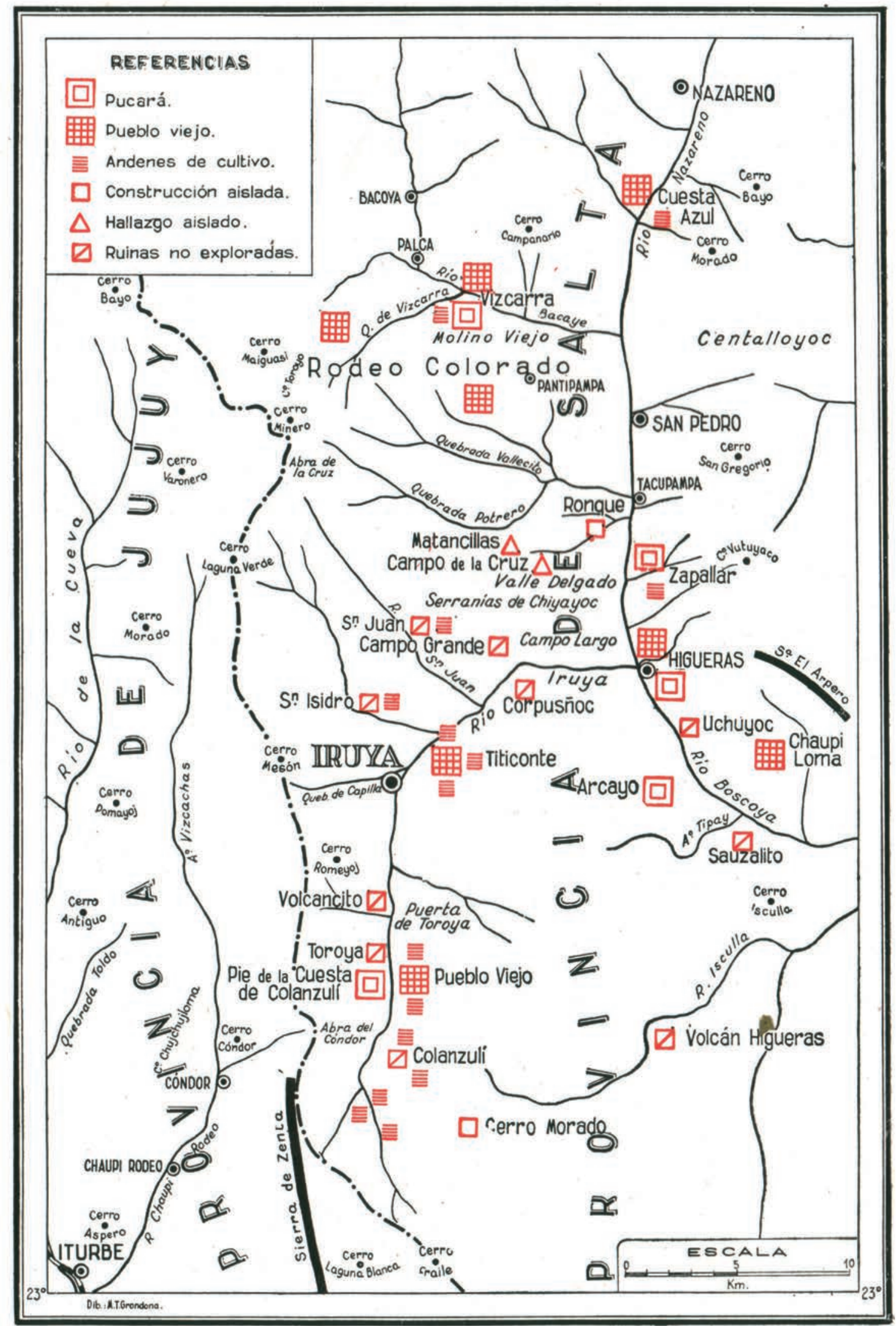

Figura 5. Un ejemplo del tipo de documentación gráfica realizada a mediados del siglo XX para el relevamiento de los restos de antiguas instalaciones puneñas (Márquez Miranda 1940: 55). 
Todos estos hallazgos de instalaciones, que evidencian patrones de poblamiento diferentes y distintos tipos de enterratorio, van conformando el cuadro cronológico de este ambiente ecológico, donde se presentan una serie de yacimientos con características muy definidas que permiten identificar las etapas de desarrollo de las diversas culturas que aquí se han asentado (Cigliano y Raffino 1977: 162).

Además, los trabajos realizados en Tastil utilizaron exitosamente las fotografías aéreas como herramienta para el análisis del crecimiento urbano del sitio, metodología que había sido utilizada por primera vez en el país unos pocos años antes por González (1956) para el reconocimiento y análisis de sitios arqueológicos con arquitectura.

Y si bien no desarrolló trabajos en el terreno, no puede dejar de mencionarse para la segunda mitad del siglo XX la publicación en 1964 de Ciudades precolombinas (Hardoy 1964), por el impacto que tuvo en la arqueología del NOA. Como resultado de un extenso análisis de casos, el autor definió los criterios que debían cumplir las instalaciones de la región para ser consideradas como urbanas, y estos fueron luego aplicados por arqueólogos que sí exploraron de modo directo los rasgos del registro arquitectónico.

\section{MODELO 4 - RESTAURACIÓN DE SITIOS}

El último conjunto identificado corresponde a trabajos que dan cuenta de la restauración y/o reconstrucción parcial de las ruinas de sitios arqueológicos como parte de un proceso que culminará con su exhibición al públi$\mathrm{co}^{6}$. Si bien son apenas unos pocos casos los incluidos en este modelo, estimamos relevante mencionarlos dada la importancia asignada desde la arqueología de la arquitectura a la relación entre investigación arqueológica y restauración (Caballero Zoreda 2004).

El antecedente más significativo corresponde a la restauración del Pucará de Tilcara, una instalación multicomponente de unas diez hectáreas de superficie ubicada a más de $2400 \mathrm{~m}$ s. n. m. en la provincia de Jujuy. Relevada por primera vez en 1908 por Ambrosetti y Debenedetti, por los siguientes dos años ambos

\footnotetext{
6 Para un análisis detallado de las implicancias teórico-metodológicas de las restauraciones realizadas en el NOA en el siglo XX ver Schávelzon (1990).
}

excavaron el interior de algunas de sus cientos de "casas" y analizaron las características de su arquitectura, aunque sin generar una planimetría general del sitio (Zaburlín 2009: 92). En 1910 Debenedetti, por primera vez en el país, inició la restauración de un sector de las ruinas (Debenedetti 1930: 136); los trabajos fueron acotados y solo abarcaron unos pocos recintos del sitio. La intervención -una especie de anastilosis, como señaló Schávelzon (1993) - fue notablemente respetuosa y cuidadosa del original para su época, ya que:

Ningún cimiento fue modificado ni alterada en lo más mínimo la estructura de ninguna construcción existente. Los trabajos se iniciaron rehaciendo las murallas de la terraza más baja [...] por el rumbo este. Para levantar las paredes de los edificios y consolidar los cimientos en parte dislocados se emplearon las mismas piedras que por su posición y tamaño era evidente que habían pertenecido a las viejas e inmediatas construcciones (Debenedetti 1930: 139).

A fines de la década de 1940, Casanova retomó los trabajos en el sitio, continuando las excavaciones y proponiendo una nueva intervención, esta vez de reconstrucción y de patrimonialización a gran escala, que afectó de modo drástico las características de las ruinas:

La altura que se ha dado a cada vivienda es un tanto convencional, basada en las paredes más altas que se han encontrado y en observaciones hechas en otros yacimientos de la quebrada. Debe advertirse también que en los últimos recintos del occidente del Pucará los muros son algo más anchos que los originales; no ha podido evitarse esta alteración porque la trepidación que los pesados trenes de carga producen al pasar a muy corta distancia derrumbó las primeras casas que se restauraron allí; los indígenas que no tuvieron ese problema hicieron sus casas con paredes menos anchas (Casanova 1968: 23).

Las falencias técnicas del proyecto -incluyendo la colocación de techos en varias docenas de estructuras en las cuales no se había registrado evidencia alguna que indicara sus características originales- pueden ser en gran medida explicadas por la falta de conocimiento en el tema a nivel nacional, y fueron acompañadas por la creación de un centro de investigaciones y un museo y la habilitación de un camino de acceso al sitio que facilitó la llegada del público al sitio (Schávelzon 1990: 87). 


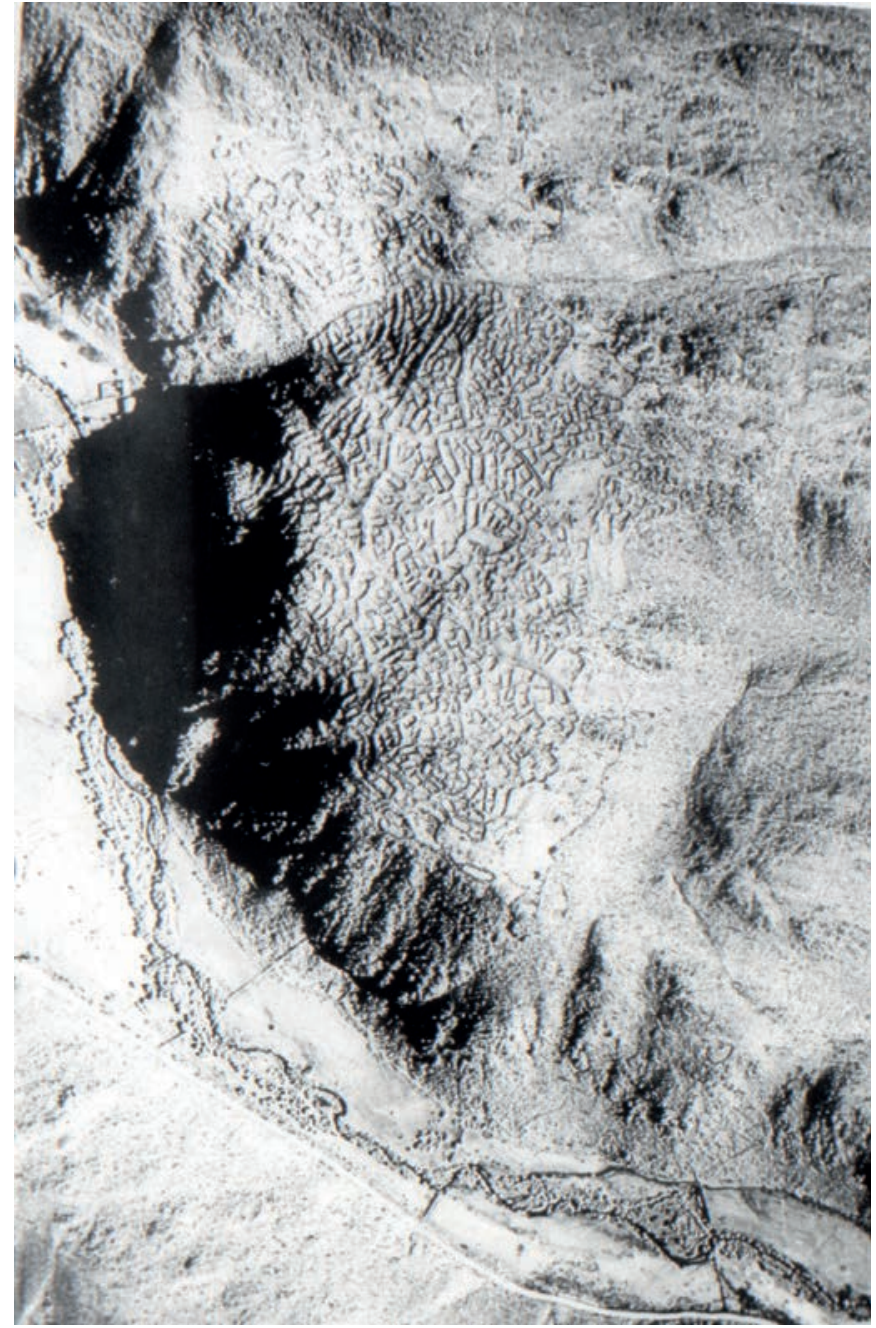

Figura 6. (a) Fotografía aérea de la ciudad de Tastil tomada en la década de 1970 (Cigliano 1973: 22) y (b) planimetría del sitio realizada por Alvis durante los trabajos en el terreno (tomado de Raffino 2007: 159).

El segundo caso que mencionaremos brevemente es la restauración que De la Fuente llevó adelante en la década de 1970 en Vinchina, La Rioja; cabe aclarar que no fue posible hallar ningún tipo de publicación o texto inédito que diera cuenta de esta intervención pero que es conocida por los arqueólogos que a posteriori trabajaron en la región (Calegari et al. 2019: 16). Las llamadas "estrellas de Vinchina" eran un conjunto de siete geoglifos, estructuras tipo plataforma circular sobreelevada, de entre 11 a $26 \mathrm{~m}$ de diámetro, construidas mediante la acumulación de piedras de color blanco, negro y rojo, que se alternaban formando triángulos (De la Fuente 1973b: 154); la parte superior de las estructuras "se encontraba levemente deprimida presentando en el centro un pequeño círculo de piedras marrones al que se accede a través de un estrecho corredor" (Calegari et al. 2019: 14). De la Fuente realizó excavaciones estratigráficas en el sitio y analizó el material entonces recuperado

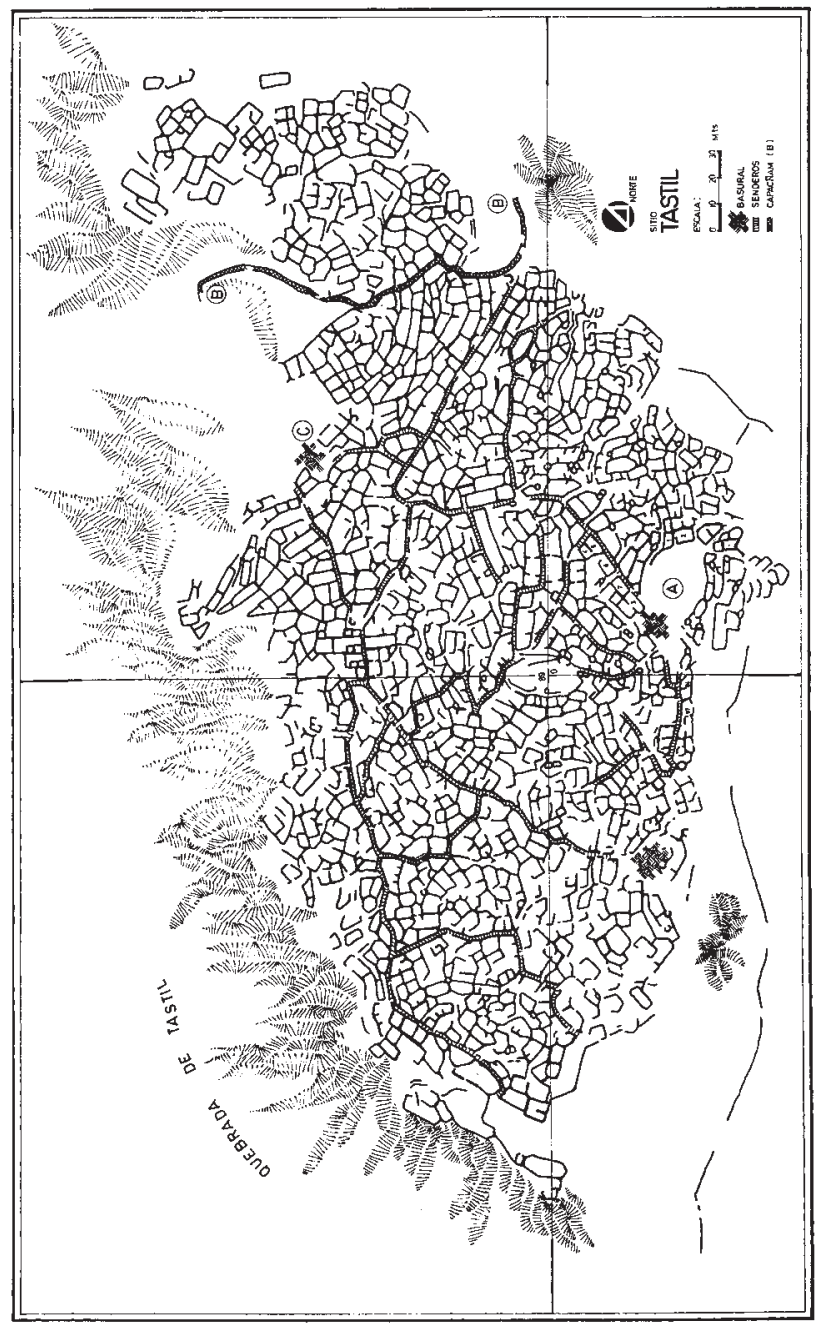

(1973a) pero, como decíamos, no proporcionó datos sobre el estado de la construcción antes de su intervención, en qué consistió la misma o qué tipo de materiales y criterios fueron empleados para ello. Sin embargo, cuarenta años después, seis de las siete estructuras han desaparecido casi por completo como resultado del crecimiento urbano de una población cercana y del uso indiscriminado de la superficie del sitio para diversos propósitos, mientras que la plataforma restaurada por el investigador aún se conserva. Ello permite estimar que futuros estudios que continúen explorando los posibles significados de la construcción de esta particular estructura puedan también recuperar datos sobre su proceso de restauración.

Como tercer caso del modelo mencionaremos la restauración, iniciada en el año 1977 bajo la dirección de Pelissero y Difrieri, de las ruinas de Quilmes, una ciudad fortificada preincaica de unas treinta hectáreas 
de superficie ubicada en Tucumán a casi 2000 m s. n. m. Si bien como pudo notarse el sitio había sido objeto de relevamientos arqueológicos a comienzos del siglo XX, estos no fueron retomados luego ni se profundizó en el conocimiento de las estructuras del sitio y la intervención de la década de 1970 solo consideró la realización de nuevas excavaciones a posteriori de las tareas de restauración, meramente con el objetivo de obtener piezas para el museo de sitio (Pelissero y Difrieri 1981: 15). Ello generó fuertes cuestionamientos por parte de otros arqueólogos, que estimaban que, tal y como lo sugería la normativa internacional entonces vigente, la excavación y demás procedimientos de obtención sistemática de información debían preceder a toda otra intervención.

Quilmes fue, sin duda, el proyecto de restauración arqueológica más cuestionado de todo el NOA, para el que "no hay un solo dato publicado sobre procedimientos, técnicas o posturas teóricas acerca de la restauración o de los trabajos realizados" (Schávelzon 1990: 91). El criticado proyecto

... fue capaz de trasformar, alterar y destruir un proceso de revalorización patrimonial, que debería haber comenzado como un proceso de investigación general, para arribar a diferentes conclusiones, entre las cuales podría haber estado la posibilidad de evaluar la transformación de un sitio arqueológico en un recurso turístico. Aquí el proyecto fue planteado al revés, se partió de una necesidad (recomponer una imagen y generar un recurso turístico/económico) [...] El grado de incoherencia es tal que si bien es evidente que lo hecho en Quilmes es una reconstrucción, en la obra citada se lo confunde con anastilosis, sin embargo resulta imposible de creer que los autores no entendían la diferencia entre una y otra. Básicamente la anastilosis es un proceso que permite la reconstitución o rearmado de elementos arquitectónicos llevándolos a su posición inicial, siempre que esté debidamente documentado ó comprobado el estado original de éstos, de manera tal que el resultado final sea similar al estado ó composición original del muro (Sosa 2008: 12).

También en este caso la restauración fue acompañada de una propuesta para la construcción de un museo, servicios y centro de visitantes - proyectados notablemente cerca del conjunto arqueológico- aunque se concretaron recién casi veinticinco años después y se realizaron nuevamente envueltos en polémicas derivadas de la falta de investigación arqueológica en las ubicaciones que iban a impactar los nuevos edificios.

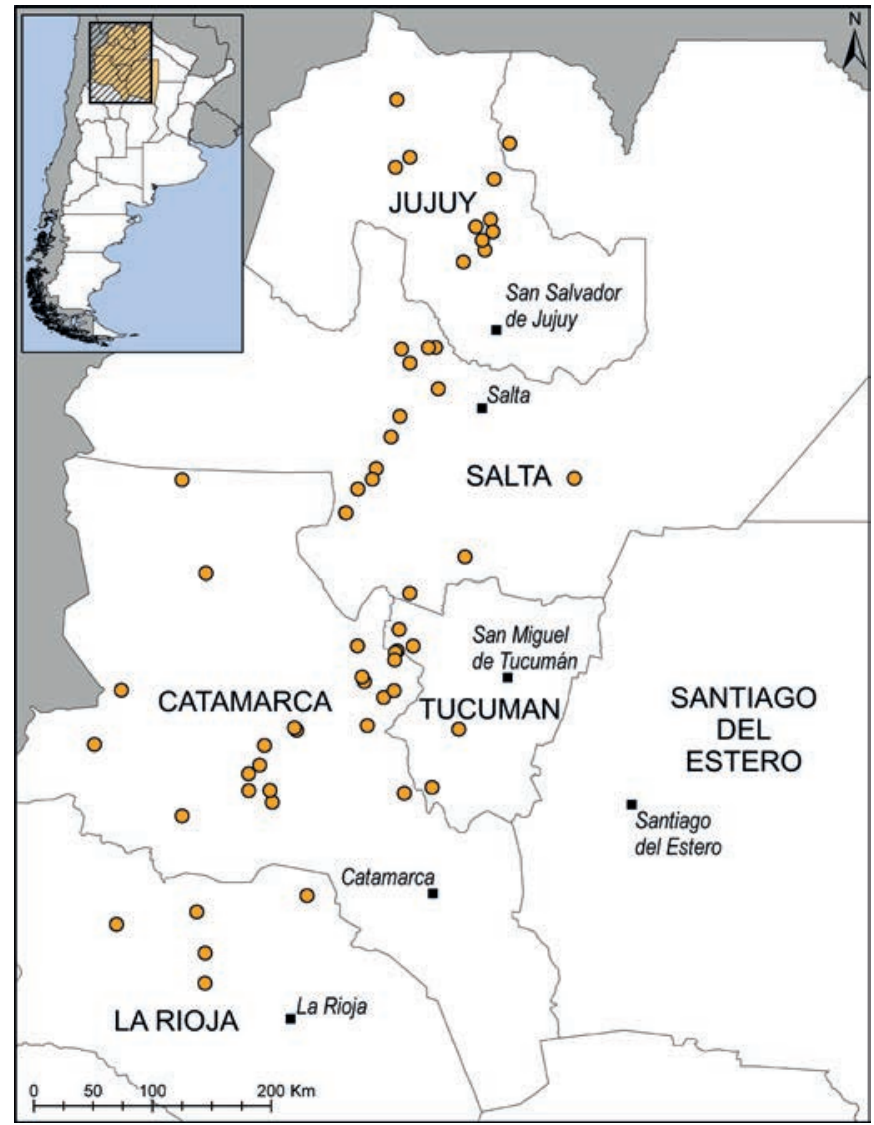

Figura 7. Ubicación en el NOA de los 58 sitios mencionados por los 33 autores revisados que se ocuparon de problemáticas relacionas al registro arquitectónico (D. Gobbo).

\section{CONSIDERACIONES FINALES}

Al comienzo del artículo propusimos que, si bien de modo poco sistemático y metodológicamente diverso, desde fines del siglo XIX la arqueología del NOA se interesó por el estudio de los restos arquitectónicos, y planteamos que la revisión de una muestra arbitraria de textos publicados daría sustento a tal hipótesis. El resultado de la revisión superó por mucho nuestras expectativas, ya que no solo proporcionó evidencia de que -con limitaciones, falencias y errores- la práctica arqueológica en la región se interesó por el análisis arquitectónico, sino que lo hizo de modo sostenido hasta el punto de permitir organizar los trabajos en modelos de análisis. Pero, mucho más interesante aún, fue posible reconocer que la perspectiva desde la cual muchos de los autores plantearon el desarrollo de sus estudios conecta de modo directo con los lineamientos actuales de la arqueología de la arquitectura. No desde lo metodológico -aunque las propuestas de algunos trabajos resultan notablemente actuales- pero sí desde lo teórico 
y conceptual. Y no pretendemos implicar con esto que las interpretaciones elaboradas en distintos momentos por distintos autores fueran precisas o que se mantengan vigentes, sino que evidencian un interés manifiesto de la disciplina por estudiar las prácticas constructivas y formas de uso del espacio como estrategia para generar interpretaciones sobre conductas cotidianas, modos de vida y organización social de los grupos que produjeron dicha arquitectura (Taboada 2016: 4). Si la arqueología de la arquitectura fue y puede ser mucho más que lectura de paramentos, y si no es el objeto arquitectónico ni la exploración arqueológica lo que importan sino su potencial para resolver problemas históricos y proporcionar datos sobre los procesos de cambio de una sociedad (Caballero Zoreda 2002: 85), entonces la historia de la arqueología del NOA tiene buenos ejemplos que ofrecer como antecedentes. Y, por supuesto, mucho trabajo aún por hacer, por lo que solo resta hacer caso a la sugerencia de Raffino de aprovechar la exuberante información arquitectónica de los sitios del NOA (Raffino 1988: 193) para construir cada vez más y mejores modelos que den cuenta de la vida de las poblaciones que alguna vez lo habitaron.

\section{AGRADECIMIENTOS}

El presente texto es el resultado de un trabajo de investigación realizado para el Workshop Arqueología de la Arquitectura: nuevos retos metodológicos y su aplicación en Europa y América latina, organizado por la Cátedra Unesco de Paisajes Culturales y Patrimonio - Centro de Investigación Micaela Portilla Ikergunea, Universidad del País Vasco; gracias a los colegas del Centro por la invitación. Gracias también a Daniel Schávelzon por su paciente respuesta a mis consultas, a Diego Gobbo por su auxilio en el procesamiento de imágenes y a Fernando Aliata por aclararme nociones arquitectónicas que me eran esquivas.

\section{BIBLIOGRAFÍA}

Alfaro, L. y Suetta, J. 1970: "Nuevos aportes para el estudio del asentamiento humano en la Puna de Jujuy. Revisión del Pucará de Rinconada", Antiquitas, 10, pp.1-10.

Ambrosetti, J. B. 1897: La antigua ciudad de Quilmes (Valle Calchaquí). La Buenos Aires, Imprenta, Papelería y Encuadernación, Buenos Aires.

Ambrosetti, J. B. 1903: Arqueología colonial - La Hacienda de Molinos. Valles Calchaquies (provincia de Salta). Imprenta y Casa Editorial de Coni Hermanos, Buenos Aires.
Ambrosetti, J. B. 1906: Exploraciones arqueológicas en la Pampa Grande. Publicaciones de la Facultad de Filosofía y Letras, 1, Buenos Aires.

Ambrosetti, J. B. 1907: Exploraciones arqueológicas en la ciudad prehistórica de La Paya (Valle Calchaquí, Provincia de Salta). Publicaciones de la Sección Antropología de la Facultad de Filosofía y Letras, 3, Buenos Aires.

Ambrosetti, J. B. 1912: "Resultado de las exploraciones arqueológicas en el Pukará de Tilcara (Provincia de Jujuy)", en Actas y Memorias del XVII Congreso Nacional de Americanistas, pp. 497-498. Buenos Aires.

Ardissone, R. 1937: "Silos de la quebrada de Humahuaca", Relaciones de la Sociedad Argentina de Antropología, 1, pp. 117-143.

Azkarate Garai-Olaun, A. 2013: "La construcción y lo construido. Arqueología de la Arquitectura", en J. A. Quirós Castillo (ed.), La materialidad de la Historia. La arqueología en los inicios del siglo XXI, pp. 271-298. Akal, Madrid.

Boman, E. 1908: Antiquitées de la région Andine de la République Argentine et du désert d'Atacama, I-II. Imprimerie Nationale, Paris.

Boman, E. 1916: "El Pucará de los sauces. Una Fortaleza de los antiguos Diaguitas en el departamento de Sanagasta, provincia de La Rioja", Physis - Revista de la Sociedad Argentina de Ciencias Naturales, II, pp. 136-145.

Bruch, C. 1911: Exploraciones arqueológicas en las provincias de Tucumán y Catamarca. Universidad Nacional de La Plata, Imprenta Coni Hermanos, Buenos Aires.

Caballero Zoreda, L. 2002: "Sobre límites y posibilidades de la investigación arqueológica de la arquitectura. De la estratigrafía a un modelo histórico", Arqueología de la Arquitectura, 1, pp. 83-100.

Caballero Zoreda, L. 2004: "Una experiencia en Arqueología de la Arquitectura", Arqueología de la Arquitectura, 3, pp. 127-143.

Cáceres Freyre, J. 1937: "El Fuerte del Pantano", Relaciones de la Sociedad Argentina de Antropología, 1, pp. 107-116.

Cáceres Freyre, J. 1955: "El Fuerte del Pantano. Datos para su historia (Siglos XVII y XVIII)", Meridiano, 66, pp. 1-22.

Caggiano, M. A. y Sempé, M. C. 1994: América: prehistoria y geopolitica. Editorial TEA, Buenos Aires.

Calegari, A.; Spengler, G y de Acha, S. 2019: "Estrellas riojanas, geoglifos del norte de la provincia de La Rioja, Argentina”, Boletín del Museo Chileno de Arte Precolombino, 24, (1), 11-34.

Casanova, E. 1933: "Tres ruinas indígenas de la Quebrada de la Cueva", Anales del Museo Nacional de Historia Natural "Bernardino Rivadavia", XXXVII, pp. 255-320.

Casanova, E. 1968: El Pucara de Tilcara. (Antecedentes, Reconstrucción, Guía). Universidad de Buenos Aires, Facultad de Filosofía y Letras, Museo del Pucara de Tilcara, Buenos Aires.

Cigliano, E. (ed.) 1973: Tastil, una ciudad preincaica argentina. Editorial Cabargó, Buenos Aires.

Cigliano, E. y Raffino, R. 1975: “Arqueología en la vertiente occidental del Valle Calchaquí medio", Relaciones de la Sociedad Argentina de Antropologia, IX, pp. 47-58.

Cigliano, E. y Raffino, R. 1977: "Tastil; un modelo cultural de adaptación, funcionamiento y desarrollo de una sociedad urbana prehistórica", Relaciones de la Sociedad Argentina de Antropología, VII, pp. 159-181.

De Aparicio, F. 1937. "La Tambería de los Cazaderos", Relaciones de la Sociedad Argentina de Antropología, 1, pp. 77-88.

De Aparicio, F. 1940-1942. "La Tambería de Rincón del Toro", Publicaciones del Museo Etnográfico, 4, pp.17-57. Facultad de Filosofía y Letras, Universidad de Buenos Aires.

De la Fuente, N. 1972: "Investigaciones arqueológicas en la quebrada de Chañarmuyo", Antiquitas, 15, pp. 1-10.

De la Fuente, N. 1973a. "Informe arqueológico sobre el Valle de Vinchina, provincia de La Rioja", Revista del Instituto de Antropología, IV, pp. 95127.

De la Fuente, N. 1973b: "El yacimiento arqueológico de Guandacol, Provincia de La Rioja", Revista del Instituto de Antropología, IV, pp. 151-167.

Debenedetti, S. 1908: Excursión arqueológica a las ruinas de Kipón (Valle Calchaquí - Provincia de Salta). Sección Antropológica, Facultad de Filosofía y Letras, Buenos Aires. 
Debenedetti, S. 1918: Las ruinas prehispánicas de El Alfarcito (departamento de Tilcara, provincia de Jujuy). Imprenta y Casa Editora Coni, Buenos Aires.

Debenedetti, S. 1919: "Los yacimientos arqueológicos occidentales del Valle de Famatina (provincia de La Rioja)", Physis, III, 15, pp. 386-404.

Debenedetti, S. 1930: Las ruinas del Pucará de Tilcara, Instituto de Antropología, Buenos Aires.

Fernández, J. 1982: Historia de la Arqueología Argentina. Talleres Gráficos del Centro de Economía, Legislación y Administración del Agua, Mendoza.

Furque, H. 1900. "Las ruinas de Londres de Quimivil (Catamarca)", Anales de la Sociedad Cientifica Argentina, L, pp. 166-171.

González, A. R. 1954a: "Las ruinas de Loma Rica y alrededores", Publicaciones Técnicas de Natura 5, 1, pp. 75-90.

González, A. R. 1954b: "La casa pozo en el N. O argentino", Revista del Museo de Mar del Plata, 1, pp. 122-132.

González, A. R. 1956: "La fotografía y el reconocimiento aéreo en las investigaciones arqueológicas del N. O. Argentino", Anales de Arqueología y Etnología, XII, pp. 41-62.

González, A. R. 1966: "Las ruinas del Shincal”, en Actas del I Congreso de Historia de Catamarca, III, pp. 15-28. Catamarca

González, A. R. 1979: "Dinámica cultural del N.O. Argentino. Evolución e Historia en las culturas del N.O. Argentino", Antiquitas, 28-29, pp. 1-15.

González, A. R. 1985: "Cincuenta años de arqueología del Noroeste Argentino (1930-1980): apuntes de un casi testigo y algo de protagonista", American Antiquity, 50 (3), pp. 505-517.

González, A. R. y Núñez Regueiro, V. 1960: “Apuntes preliminares sobre la arqueología del Campo del Pucará y alrededores (Departamento Andalgalá-Catamarca)", Anales de Arqueología y Etnología, 14-15, pp. 115-162.

Gramajo, A. 1976: "La primitiva ciudad de San Miguel de Tucumán en Ibatín: estudio histórico-arqueológico", Relaciones de la Sociedad Argentina de Antropología, X, pp. 141-166.

Greslebin, H. 1940. Arqueografia de la Tambería del Inca de Chilecito (La Rioja. Argentina). Un ensayo de urbanismo prehispánico. Sociedad Central de Arquitectos, Buenos Aires.

Hardoy, J. 1964: Ciudades precolombinas. Ediciones Infinito, Buenos Aires.

Igareta, A. 2009: "Capítulo 3 - La redefinición del espacio construido como indicador de superposición entre instalaciones indígenas e hispánicas durante el período colonial", en Jorge Buján (comp.), América Antigua, pp. 144-173. Editorial Nobuko, La Plata.

Krapovickas, P. 1955: El yacimiento de Tebenquiche (Puna de Atacama). Publicaciones del Instituto de Antropología, III. Universidad de Buenos Aires, Facultad de Filosofía y Letras, Buenos Aires.

Krapovickas, P. 1970: "Observaciones sobre la Arqueología del noroeste de la Puna Argentina", Relaciones de la Sociedad Argentina de Antropología, 5, pp. 117-122.

Lafón, C. 1954: Arqueología de la Quebrada de La Huerta (Quebrada de Humahuaca, provincia de Jujuy). Publicaciones del Instituto de Arqueología, I. Universidad Nacional de Buenos Aires, Facultad de Filosofía y Letras, Buenos Aires.

Lafón, C. 1958: "De la cronología y origen de las culturas del Noroeste argentino", Revista del Museo de La Plata (Nueva Serie), V, pp. 1-27.

Lafone Quevedo, S. 1898: "El Barco y Santiago del Estero. Estudio históricotopográfico", Boletín del Instituto Geográfico Argentino, XIX, pp. 3-36.

Lafone Quevedo, S. 1902: "Las ruinas de Pajanco y Tuscamayo entre Siján y Pomán, provincia de Catamarca", Revista del Museo de La Plata, 10, pp. 259-264.

Lahitte, H. y Calandra, H. 1975: Codificación arqueológica. Parte I: viviendas. Tipología elaborada sobre tarjetas perforadas. Informe CONICET, División Arqueología, Museo de La Plata, La Plata.

Lange, G. 1892a: "Las ruinas del pueblo de Watungasta", Anales del Museo de La Plata, Sección Arqueología, II, pp. 3-5.

Lange, G. 1892b: "Las ruinas de la fortaleza del Pucará", Anales del Museo de La Plata, Sección Arqueología, III, pp. 3-5.

Liberani, I. y Hernández, R. [1877] 1950: Excursión arqueológica en los Valles de Santa María, Catamarca. Universidad Nacional de Tucumán, San Miguel de Tucumán.
Madrazo, G. y Ottonello, M. 1966. Tipos de instalación prehispánica en la región de la Puna y su borde. Monografías, 1. Museo Etnográfico Municipal Dámaso Arce, Olavarría.

Márquez Miranda, F. 1937: "Arquitectura aborigen en la provincia de Salta”, Relaciones de la Sociedad Argentina de Antropología, 1, pp. 141-166.

Márquez Miranda, F. 1940: Los aborígenes de América del Sur. Colección Historia de América publicada bajo la dirección de Ricardo Levene. W. M. Jackson Inc. Editores, Buenos Aires.

Nastri, J. 2001: "Interpretando al describir: la arqueología y las categorías del espacio aborigen en el valle de Santa María (noroeste argentino)", Revista Española de Antropología Americana, 31, pp. 33-58.

Nielsen, A. 2001: "Evolución social en la Quebrada de Humahuaca (AD 700-1536)", en E. Berberián y A. Nielsen (eds.), Historia Argentina Prehispánica, Tomo I, pp. 171-264. Editorial Brujas, Córdoba.

Núñez Regueiro, V. 1971: "La cultura Alamito de la subárea Valliserrana del Noroeste Argentino", Journal de la société des américanistes, LX, pp. 7-54.

Núñez Regueiro, V. 1974: "Conceptos instrumentales y marco teórico en relación al análisis del desarrollo cultural del Noroeste Argentino", Revista del Instituto de Antropología, V, pp. 169-190.

Páez, G. 2002: "Relevamientos arquitectónicos en arqueología urbana y conservación del patrimonio construido", en Actas del Congreso Nacional de Arqueología Histórica, pp. 473-485. Editorial Corregidor, Buenos Aires

Pelissero, N. y Difrieri, H. A. 1981. Quilmes. Arqueología y Etnohistoria de una ciudad prehispánica. Gobierno de la Provincia de Tucumán.

Pérez Gollán, J. A. y Heredia, O. 1975: "Investigaciones arqueológicas en el Departamento Ambato, Provincia de Catamarca", Relaciones Sociedad Argentina de Antropología, IX, pp. 59-68.

Quiroga, A. 1896: "Las ruinas de Anfama, el pueblo prehistórico de La Ciénaga", Boletín del Instituto Geográfico Argentino, 20, pp. 95-123.

Quiroga, A. 1901: "Ruinas calchaquíes, Fuerte Quemado", Anales de la Sociedad Cientifica Argentina, LII.

Raffino, R. 1975: "Potencial ecológico y modelos económicos en el N.O. argentino", Relaciones de la Sociedad Argentina de Antropología, IX, pp. 21-45.

Raffino, R. 1977: "Las aldeas del Formativo Inferior de la Quebrada del Toro", Estudios Atacameños, 5, pp. 65-109.

Raffino, R. 1988: "El data arquitectónico como unidad de análisis en modelos procesuales arqueológicos", en Precirculados de las ponencias del IX Congreso Nacional de Arqueología Argentina. Universidad de Buenos Aires, Instituto de Ciencias Antropológicas, Facultad de Filosofía y Letras, Buenos Aires.

Raffino, R. 2007. Poblaciones indigenas en Argentina. Urbanismo y proceso social precolombino. Emecé Editores, Buenos Aires.

Raffino, R. y Cigliano, E. 1973: “'La Alumbrera', Antofagasta de la Sierra. Un modelo de ecología cultural prehistórica", Relaciones de la Sociedad Argentina de Antropología, VII, pp. 241-258.

Salas, A. 1945: "El Antigal de Ciénaga Grande", Publicaciones del Museo Etnográfico, 5, Buenos Aires.

Schávelzon, D. 1990: "La restauración de la Arquitectura Prehispánica en la Argentina: notas para su historia", Runa, Archivo para las Ciencias del Hombre, XIX, pp. 83-93,

Schávelzon, D. 1993: "La restauración de sitios arqueológicos: historia de una frustración interminable", en 3er. Congreso Latinoamericano de Cultura Arquitectónica y Urbanistica. Salta, Argentina. https://www.danielschavelzon.com.ar/?p=3199_[consultado: 07/06/2019].

Schávelzon, D. 2012: La casa del Naranjo, arqueología de la arquitectura en el contexo municipal de Buenos Aires. Aspha Ediciones, Buenos Aires

Schuel, K. 1929: "Ruinas de las poblaciones de los indígenas de la provincia de Jujuy", en Actas del Congreso de Patología Regional del Norte, 5 (2), pp. 1430-1451. Misión de Estudios de Patología Regional Argentina, Jujuy.

Sempé, M. C. 1977a: "Batungasta: un sitio tardío e incaico en el valle de Abaucán (Dpto. Tinogasta-Catamarca) significación etnohistórica", en Actas y Memorias IV Congreso Nacional de Arqueología Argentina, 2, pp. 69-83. San Rafael.

Sempé, M. C. 1977b: "Caracterización de la cultura Saujil", Obra del Centenario del Museo de La Plata, II, pp. 211-235. Museo de Ciencias Naturales, Universidad Nacional de La Plata. 
Serrano, A. 1936: "Arquitectura Diaguita", Revista Geográfica Americana, 5 , pp. 51-60.

Sosa, J. 2008. “Ruinas” de Quilmes. Historia de un despropósito. Documento en línea. http://media.argentina.indymedia.org/uploads/2008/01/kilmes. pdf [consultado el 05/07/2019].

Spengler, G. 2008: Construcciones del pasado Tradiciones constructivas y representaciones del pasado. Tesis de Licenciatura. Facultad de Filosofía y Letras, Universidad Nacional de Buenos Aires. http://repositorio.filo.uba. ar/handle/filodigital/4235 [consultado el 10/09/2019].

Taboada, C. 2003: Arquitectura y sociedad en la Quebrada de Humahuaca prehispánica. Tesis doctoral, Facultad de Ciencias Naturales e Instituto Miguel Lillo, Universidad Nacional de Tucumán. https://www.academia.edu/40070568/ARQUITECTURA_Y_SOCIEDAD_EN_LA_QUEBRADA_DE_HUMAHUACA_PREHISP\%C3\%84NICA._Tesis_doctoral_2003. [consultado el 03/05/2019].
Taboada, C. 2016: "Montículos arqueológicos, actividades y modos de habitar. Vivienda y uso del espacio doméstico en Santiago del Estero (tierras bajas de Argentina)", Arqueología de la Arquitectura, 13: e040. https://doi. org/10.3989/arq.arqt.2016.003

Willey, G. 1953: Prehistoric Settlement Patterns in the Viru Valley, Peru. Bureau of American Ethnology Bulletin, 155 Smithsonian Institution, Bureau of American Ethnology, Washington, DC.

Zaburlín, M. A. 2009: "Historia de ocupación del Pucará de Tilcara (Jujuy, Argentina)", Intersecciones en Antropología, 10, pp. 89-103.

Zarankin, A. 1999: "Arqueologia de la Arquitectura: another brick in the wall", Revista do Museu de Arqueologia e Etnologia, Suplemento 3, pp. 119-128. 